\title{
Exploring the mediation role of employees' well-being in the relationship between psychosocial factors and musculoskeletal pain during the COVID-19 pandemic
}

\author{
Auditya Purwandini Sutarto ${ }^{\mathrm{a}, *}$, Titis Wijayanto ${ }^{\mathrm{b}, 1}$ and Irma Nur Afiah ${ }^{\mathrm{c}, 2}$ \\ ${ }^{a}$ Department of Industrial Engineering, Universitas Qomaruddin, Gresik, Indonesia \\ ${ }^{\mathrm{b}}$ Department of Mechanical and Industrial Engineering, Universitas Gadjah Mada, Yogyakarta, Indonesia \\ ${ }^{\mathrm{c}}$ Department of Industrial Engineering, Universitas Muslim Indonesia, Makassar, Indonesia
}

Received 10 June 2021

Accepted 3 September 2021

\begin{abstract}
.
BACKGROUND: The COVID-19 pandemic has increased some psychosocial risks which may aggravate the development of musculoskeletal disorders (MSDs) and reduced psychological well-being, two leading global occupational health problems. OBJECTIVE: This study aims to investigate whether an employee's psychological well-being mediates the relationship between the psychosocial factors (job strain, work-life balance, and job security) and the prevalence of musculoskeletal pain in the Indonesian general working population during the pandemic.

METHODS: A cross-sectional study design was employed using an online questionnaire. A total of 406 from 465 respondents were included in the final analysis.

RESULTS: It was found that $73.9 \%$ of respondents suffered from upper body part pain, $25.15 \%$ from low back pain, and $39.7 \%$ reported pain in the lower limb. Process Macro Model 4 analysis showed the significant role of well-being as a mediator in the association between work-life balance and the odds of experiencing the upper body and low back pains. However, neither the direct nor mediating effect on the relationship between job strain or job security and any musculoskeletal pains were observed. These findings suggest that specific psychosocial factors may be more relevant to be investigated in the particular context.

CONCLUSION: The use of a mediation model was able to link work-life balance to musculoskeletal complaints through well-being states in the context of the pandemic. Organizations need to mitigate poor well-being triggered by psychosocial stressors which could affect physical complaints to maintain employee's health and productivity.
\end{abstract}

Keywords: COVID-19, musculoskeletal, psychosocial, well-being, work-life balance

\section{Introduction}

The unprecedented COVID-19 pandemic has been shown to have negative consequences on employees' physical and psychological health [1,2]. It may

\footnotetext{
${ }^{1}$ ORCID ID: 0000-0001-5488-5340.

${ }^{2}$ ORCID ID: 0000-0003-2426-6180.

*Address for correspondence: Auditya Purwandini Sutarto, Department of Industrial Engineering, Universitas Qomaruddin Gresik, Gresik, Indonesia. E-mail: auditya@uqgresik.ac.id; ORCID ID: 0000-0003-0298-4165
}

exacerbate the risks of musculoskeletal disorders (MSDs) and mental well-being or stress [3-5] which are the major occupational safety and health concerns worldwide [6] and Indonesia [7], impacting significantly on organizations and national economies $[8,9]$. According to the WHO, psychological well-being or mental health problems is one of the highest contributors to reduced job involvement and absenteeism from the workplace [10] while MSDs is one of the most common causes of disability around the world, leading to early retirement from employment, decreased 
well-being, and a reduced ability to engage in society [6].

Poor psychosocial factors such as high workload, time pressure, monotonous tasks, excessive work demand, low job control, and lack of social support $[11,12]$ are found to be associated with the development of MSDs and mental well-being problems [8]. Psychosocial factors refer to interactions between and among occupational and working environments, the extra-work environment, and individual employee's characteristics that can influence physical and psychological health, work performance, and job satisfaction $[12,13]$. Experts have also characterized psychosocial risks as threats to one's mental, physical and social health, arising from work conditions, as well as organizational and relational elements that are likely to interact with mental functioning [14]. According to aforementioned definitions, a psychosocial risk should be deemed psychosocial in nature based on its origin (stressors or cause) rather than its manifestation (i.e., stress responses or strain) $[11,13,15]$.

On the other hand, to address the biomedical model limitations, the current approach of MSDs has been built based on simultaneous biological, psychological and social factors in the onset and the development of MSDs maintenance and could explain about 5-10\% of MSDs cases become chronic even when they occur in jobs with low physical demands (e.g., computer or office work) [14]. The scientific community and the major organizations involved in prevention efforts have now generally adopted the approach $[14,16]$. This biopsychosocial approach, supported by extant literature, has implied that employees' psychological health or mental well-being is a strong determinant of MSDs, implying a more complex relationship between psychosocial factors, MSDs, and well-being is beyond the simple bivariate relationships.

Scholars have proposed some different theoretical models to explain the mechanisms underlying the associations between psychosocial factors and MSDs through psychological health $[11,13,17]$. Bonger et al. [13], Sauter and Swanson [17], and Hauke, et al. [18] suggest that psychosocial factors (e.g., job strain, work-life conflict, social support, decision latitude) can affect psychological responses to stressors including cognitive, emotional, behavioral, and physiological components. These responses, in turn, may contribute to the occurrence and development of MSDs, in addition to the effects of physical ergonomic risk factors [11, 19]. Furthermore, the balance model by Carayon et al. [11] incorporates feedback loops from MSDs outcomes to stress reactions and work organizations which provide a more dynamic and holistic work system. Despite the existence of theoretical frameworks proposing the mechanism behind the links between psychosocial factors and MSDs, very few studies have been undertaken to validate these models of which findings remain inconsistent [20-24]. These conflicting findings might be partly due to the different operational definitions and measurements of the psychosocial factors.

In this current study, three psychosocial factors will be incorporated into our model: job strain, worklife balance (WLB), and job security. Reviews on both cohort [25] and cross-sectional studies [26] have shown that job strain - a combination of high demand and low control - is a crucial psychosocial factor for workers' physical and psychological health impairment. High demand occurs when there are high workloads, time pressure, and role conflict, while employees are considered as having low job control when they do not have autonomy over their work and are lack of involvement in decision-making processes $[25,27]$. During the COVID-19 crisis, evidence on the association between increased job strain and adverse work-related outcomes are increasing [28, 29].

Furthermore, another potential risk factor is worklife balance concern because there may be amplification conflict between work and life roles, compared to before the pandemic [30]. Employees must manage increased household chores and childcare because of the widespread closures of schools and daycare, as well as concerns about the health and safety of family and friends. They also deal with the increased strain that can result from emergent changes in work practices and environment. These new-found challenges have intensified work-family conflict, making worklife balance more difficult to maintain [31]. Research has shown that employees with greater WLB were better able to manage their multiple roles of responsibilities, perceived more satisfied with their jobs and life, worked more productive, and showed stronger organizational commitment, compared to those with less balance $[32,33]$. Despite evidence of the WLB influence on psychological health during the current crisis is increasing [30,34], studies examining its role as a potential risk factor outside the work environment for musculoskeletal (MS) health have not received much attention. Beyond the pandemic context, Hammig et al. [35] have suggested the exploration of the work-life imbalance issue as the important stressor and potential risk factor for MSDs and the possible 
mediating role of psychological health symptoms in this relationship.

It is also important to include job security as another risk factor because the COVID-19 crisis has caused global economic disruptions which may elevate uncertainty about the future. High levels of job insecurity can lead to low motivation and compliance with safety measures, increasing workrelated injuries [36]. Beyond the pandemic context, employees experiencing heightened job insecurities are associated with higher odds with the development of MSDs [37, 38], poor physical health [39], and worse mental health outcomes [22, 40]. In the pandemic context, a large body of evidence shows the impact of job security on psychological wellbeing $[22,41]$ but no information on the occurrence of musculoskeletal complaints.

Psychosocial risks are closely related to workrelated stress, which has been associated with a reduction in social interaction and the ability to concentrate at work, increased physiological pain and cardiovascular problems [42], and a higher incidence of mental illness [23, 43]. Previous studies have demonstrated the extent to which psychosocial factors affect the risk of having MSDs or psychological well-being $[8,37,44,45]$ as well as the interplay between well-being and MSDs [46, 47]. Nonetheless, these studies examined only the bivariate relationships between psychosocial factors and musculoskeletal (MS) symptoms, rather than directly examining the mediating role of well-being in the pathway. Furthermore, many of the above studies combined the psychosocial stressors (e.g., job demands, role conflict, lack of control, lack of reward) and stress responses (e.g., depression, anxiety, physical stress symptoms, well-being) instead of distinguished between the stressors and the responses [37, 44, 45], making it difficult to evaluate their relative impacts on MS symptoms. Besides, psychosocial stressors refer to aspects of occupational, working environment, and individual characteristic (i.e., causes) whereas strains denote employees' negative reactions to these working conditions (i.e., effect) [15]. This distinctiveness suggested both terms should not be lumped together.
In one of the few studies in which the mediation path was examined, psychological strain mediated the relationship between workload and upper body and lower back MSDs among call center operators [24] while Eatough and colleagues [21] have found significant influences of employees strain (e.g., depression, anxiety), linking between the specific psychosocial work stressors and work-related MSDs.

As described earlier, various conceptual models of MSDs have proposed a more complex relationship on the prevalence and development of MS pains, involving several pathways between psychosocial stressors and strain or stress response as a potential mediator $[11,13,17,19]$. One explanatory model by Hauke et al. [19] is based on idea that psychosocial stressors evoke psychological strain and would depend on individual characteristics, available resources, and coping strategies. Such reactions may exert the chemical and biological processes that could increase muscle tension in the short term and might increase the risk of long-term manifestation of MSDs. Another explanation for why strain may act as a mediator between psychosocial stressors and MSD is by altering hormonal, circulatory, and respiratory responses, which can amplify the effects of physical risk factor $[48,49]$. Finally, strain responses such as irritability and frustration may increase hazardous behavior that raises the risks of MSDs (e.g., improper work method, forceful work technique) [11]. Thus, theoretically, psychological strain may play a mediating role on the relationship between psychosocial work stressors and MSDs.

Strain itself may be manifested into physiobiological, psychological, and behavior responses [11, 13, $17,19]$, however in the current study's framework we focused on the psychological or emotional aspects, from henceforth referenced as mental or psychological well-being. Psychological well-being is the combination of positive feeling (e.g., happiness, contentment), emotions (e.g., interest, engagement), and functioning effectively regardless of negative emotions that are a normal part of life [50].

Considering the aforementioned reasons, we aimed to fill the research gap by integrating specific

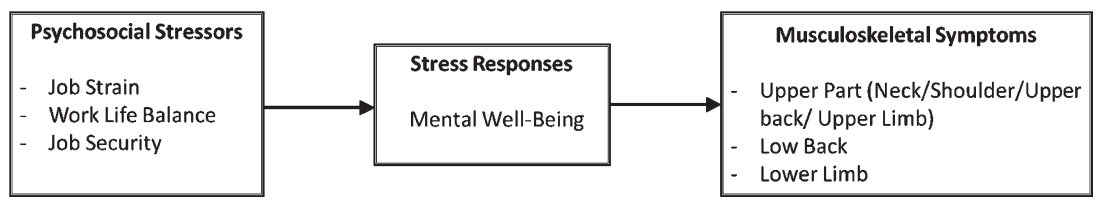

Fig. 1. Conceptual model linking between psychosocial stressors and musculoskeletal symptoms through psychological well-being. 
psychosocial factors during the COVID-19 pandemic and the pathway by which psychological well-being may impact the prevalence of MS symptoms, as illustrated in our conceptual model in Fig. 1. This model is consistent with multiple models [11, 13, 17, 19] described earlier

This present study can contribute to the existing literature by providing a more thorough understanding of mechanisms linking certain psychosocial factors with MS symptoms during the specific context of the COVID-19 pandemic. More precisely, we formulate the following hypotheses:

- Hypothesis H1. Employees' job strain, work-life balance, and job security will have significant effects on the prevalence of musculoskeletal pains.

- Hypothesis H2. Employees' job strain, work-life balance, and job security will have significant effects on their psychological well-being.

- Hypothesis H3. Employees' psychological wellbeing will have significant negative effects on the prevalence of musculoskeletal pains.

- Hypothesis H4. Employees' psychological wellbeing will mediate the relationship between psychosocial factors (i.e., job strain, worklife balance, job security) and musculoskeletal pains

\section{Materials and methods}

\subsection{Participants}

A cross-sectional design was employed by collecting online survey data through various social media platforms and authors' networks from October to November 2020. For the time sensitivity of the pandemic and resource constraints, we adopted a combination of non-probability convenience and snowball sampling strategies by encouraging respondents to pass the questionnaire to their peers. All participants were informed about the aims of this study, the confidentiality of the responses and data handling, and their voluntary participation. The study population comprises Indonesian general working population. The inclusion criteria were Indonesian employees above 18 years old and living in Indonesia at the time of the pandemic. The exclusion criteria were reporting a confirmed or suspected COVID-19 illness, having chronic disease, and mental illness. After removing incomplete and ineligibility responses, the final sample comprised 406 from 465 respondents (completion rate $87.3 \%$ ).

A demographic questionnaire was used for collecting personal details including gender, age, education level, job tenure, job classification (white and bluecollar), marital status, number of children, and weight and height (calculated as BMI).

The study was approved by the Health Research Ethics Committee Universitas Jember, Indonesia (29/UN25.1.14/KEPK/2020).

\subsection{Measures}

\subsubsection{Psychosocial factors}

The job strain model was derived from the original Job Content Questionnaire (JCQ) [51] which consists of five items on job demand and nine on job control. In the present study, we used two questions on job demands: (a) "Do you have enough time to complete your assignments at work?" and (b) "Are there contradictory demands involved in your job?" and two on job control: (c) "Are you free to decide what needs to be done at work?" and (d) "Are you free to decide how your work is to be carried out?" All items were rated as 1 (never), 2 (rarely), 3 (sometimes), 4 (usually), and 5 (always). The use of a partial scale compared with a complete, multi-item job demands and control instrument has been validated having a high correlation to a complete instrument and assessing the same underlying concepts as the complete instrument $[52,53]$. The internal consistency (Cronbach $\alpha$ ) of the job demands questions in the present study was 0.54 and for job control 0.79. Considering the low internal value of job demand scale because of the partial scale with fewer items used in this study, we further reported the mean of inter-item correlation which accounted for 0.37 . This indicated homogeneity or unidimensional of the scale as suggested by Briggs and Cheek [54] in 0.2 to 0.4 range. The composite score of each scale was calculated by summing the item scores (for job demands, question (b) was reversed to ensure higher scores indicate more demands). To analyze job strain responses, we categorized results by first dichotomizing (low vs high) the job demands and job control scale at the median values of the total scores of each scale [48, 55]. Job strain quadrants were then constructed from the possible combination of the two dichotomized scales into four quadrants: (i) high strain (high job demands, low job control), (ii) low strain (low job demands, high job control), (iii) passive job (low job demands, low job control), and (iv) active job (high job demands, high job control), as shown in Fig. 2. 


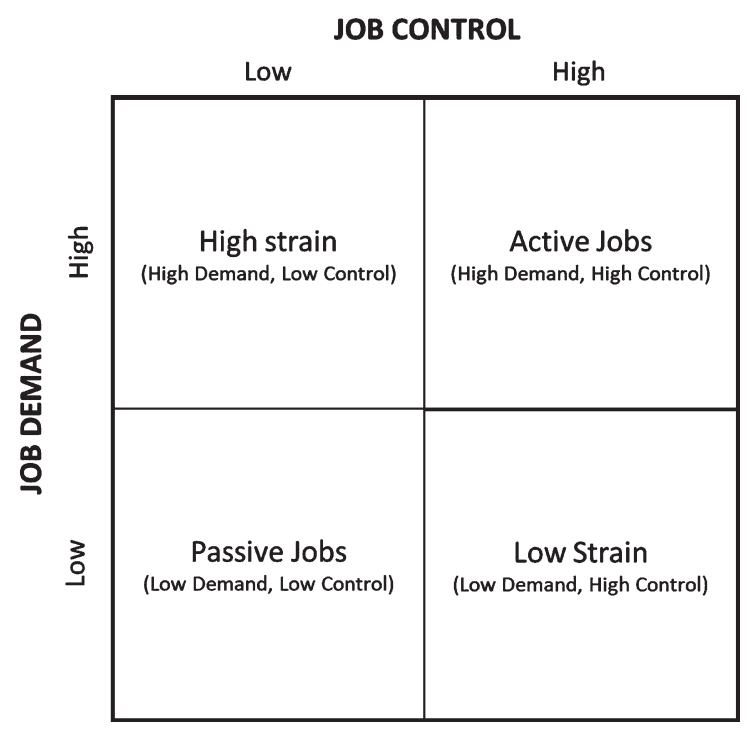

Fig. 2. Job strain categories.

Work-life balance (WLB) was assessed using three items grouped into a single factor (e.g., "I manage to balance the demands of my work and personal/family life well") [33]. Items for this scale were measured on a 5-point Likert scale ranging from 1 ("completely disagree") to 5("completely agree). The composite value was calculated by averaging all items, with higher scores indicating higher values of WLB. The WLB has shown good internal consistency in previous studies conducted in different countries [33]. The Cronbach $\alpha$ value for the present study was 0.73 .

The job insecurity was examined using a single item on a scale from 1 (not at all) to 5 (very worried): "How worried are you about the effect of coronavirus, COVID-19, on your employment?" [40]. Higher scores correspond to more insecurity perception.

\subsubsection{Well-Being}

WHO-five Well-Being Index (WHO-5) was employed to measure psychological well-being [56]. Respondents were asked to rate how well the presence of five positive feelings in the last two weeks on a 6-point scale ranging from all of the time (5 points) to at no time ( 0 points). The total raw score was multiplied by four and transformed into a percentage scale ranging from 0 (absence of well-being) to 100 (maximal well-being), following the scoring principle in a recent systematic review [56]. The WHO-5 has been widely used in the field of stress research to assess emotional well-being in occupational health setting as well as the association between psychosocial conditions and well-being $[56,57]$. This scale can also be applied as a screening tool for depression in clinical trials [56]. The internal reliability of Cronbach $\alpha$ of the Indonesian version WHO-5 was 0.92 .

\subsubsection{Musculoskeletal symptoms}

The Indonesian version of the Nordic musculoskeletal questionnaire was used to assess the musculoskeletal symptoms. Participants indicated whether they experienced pain, numbness, or discomfort for the last six months (i.e., during the pandemic) in any of three regions of body parts: (neck/shoulder/wrist/elbow/upper back), lower back (LB), lower limb (hip, knee, ankle). The symptoms responses were dichotomized into "yes" (1) or "no" (0) and no further questions were asked. The internal consistency for the questionnaire is 0.73

\subsection{Data analysis}

Descriptive analysis was performed using mean and standard deviation (SD) values for numeric data and frequency values for categorical data to characterize the sample. Before testing the mediation model, correlation analysis between all variables was conducted: independent $t$-test for examining the relationship between numeric and binary variables, one way-ANOVA ( $F$ statistics) for evaluating between numeric and more than two categories variable, Pearson correlation for both numeric variables, and Chi-square for both categorical variables.

PROCESS Macro model 4 version 3.5 was implemented to evaluate the statistical mediation model, as presented in Fig. 3 [58]. Five independent variables (three job strain categories with high strain as a reference, one work-life balance variable, and one job security) was executed separately for each outcome (upper part, lower limb, and low back) with gender was included as a covariate. Two regression models were employed to examine whether the association between psychosocial factors and prevalence of musculoskeletal symptoms is mediated by well-being levels. In the first ordinary least squares regression model, the PROCESS model 4 calculated the association between each psychosocial factor $(X)$ and well-being as a mediator $(M)$ (path $a$ in Fig. 1). In the second logistic regression model, the role of well-being $(M)$ (path $b$ ) and psychosocial variables $(X)$ (the direct effect or path $c^{\prime}$ ) as predictors 


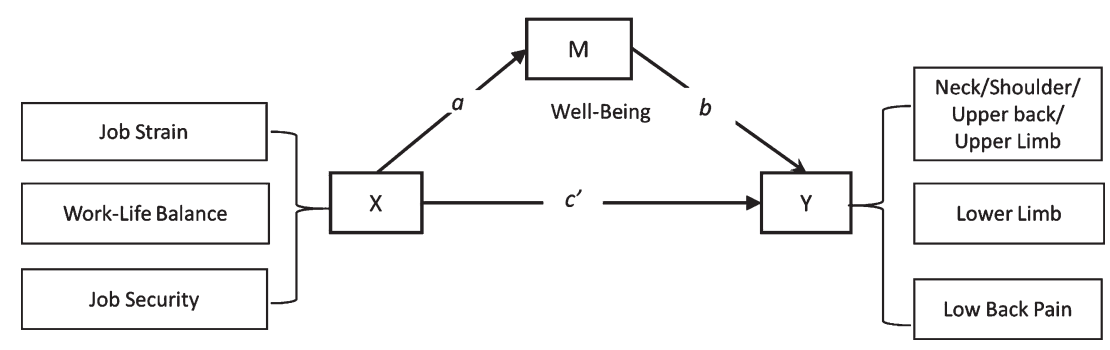

Fig. 3. Statistical model for the association of psychosocial risk factors, well-being, and musculoskeletal complaints. Path $a=$ association between each independent variable $(X)$ and a mediator $(M)$ well-being. Path $b=$ association between $M$ and each musculoskeletal region pain $(Y)$; Path $c^{\prime}=$ direct effect, association between each $X$ and outcome $Y$.

of the prevalence of musculoskeletal symptoms $(Y)$ were computed. Because there are five tests were performed simultaneously for each MS symptoms variable, a Bonferroni correction was applied, and the null hypothesis were rejected at adjusted significance level $\alpha=0.05 / 5=0.01$. The significance of the indirect effect was calculated using 99\% Bootstrap Confidence Intervals (CI) from 5,000 samples rather than usual $95 \%$ CI because of multiple tests [59]. The mediation effect is demonstrated significant when the $99 \%$ CI does not contain zero. Estimate $(\beta)$ was reported while Odd Ratio (OR) was calculated by hand $(\mathrm{OR}=\exp (\beta))$. All these analyses were performed using the Statistical Package for the Social Sciences (SPSS) version 23.0.

\section{Results}

\subsection{Demographic characteristics}

A summary of descriptive statistics is shown in Table 1 . Of the 406 participants, $52.2 \%$ were female, mean age was 37.5 years old $(\mathrm{SD}=8.58), 77.8 \%$ were married, and $65.5 \%$ had $1-3$ children. The majority of respondents (73.4\%) worked as white-collar, 26.1\% had 5-10 years of job tenure, and $80.8 \%$ worked from home.

Regarding job strain, $19 \%$ of participants reported high job strain, $37.9 \%$ low strain, $21.9 \%$ passive jobs, and $21.2 \%$ active jobs. On average, during the pandemic participants reported a relatively good work-life balance $(3.5 \pm 0.6)$, slightly higher job insecurities $(3.2 \pm 1.20)$, and moderate well-being levels (61.8. \pm 22.56$)$. Nearly $75 \%$ of the sample reported suffering from muscular pains in the neck/ shoulder/and or upper limb, $39.7 \%$ in the lower limb, and $25.15 \%$ in the low-back region (see Table 1).
Table 1

Descriptive statistics of the sample's demographic characteristics $(N=406)$

\begin{tabular}{|c|c|c|}
\hline Variable & Categories & $\begin{array}{r}\text { (Percentage) } \\
\text { or Mean (SD) }\end{array}$ \\
\hline \multirow[t]{2}{*}{ Gender } & 1. Male & $194(47.8 \%)$ \\
\hline & 2. Female & $212(52.2 \%)$ \\
\hline Age (years) & & $37.55(8.58)$ \\
\hline \multirow{4}{*}{ Education level } & 1. $<$ High school & $52(12.8 \%)$ \\
\hline & 2. Diploma & $26(6.4 \%)$ \\
\hline & 3. Bachelor & $161(39.7 \%)$ \\
\hline & 4. Post-graduate & $167(41.1 \%)$ \\
\hline \multirow[t]{5}{*}{ Job tenure } & 1. $<1$ years & $34(8.4 \%)$ \\
\hline & 2. $1-5$ years & $97(23.9 \%)$ \\
\hline & 3. 5-10 years & $106(26.1 \%)$ \\
\hline & 4. $11-20$ years & $27(6.7 \%)$ \\
\hline & 5. $>20$ years & $142(35 \%)$ \\
\hline \multirow[t]{2}{*}{ Job classification } & 1. White-collar & $298(73.4 \%)$ \\
\hline & 2. Blue-collar & $108(26.6 \%)$ \\
\hline \multirow[t]{3}{*}{ Marital status } & 1. Married & $316(77.8 \%)$ \\
\hline & $\begin{array}{l}\text { 2. Divorced/ } \\
\text { widowed }\end{array}$ & $14(3.4)$ \\
\hline & 3. Single & $76(18.7 \%)$ \\
\hline \multirow{3}{*}{$\begin{array}{l}\text { Number of children } \\
<18 \text { years old }\end{array}$} & 1.0 & $120(29.6 \%)$ \\
\hline & 2. $1-3$ & $266(65.5 \%)$ \\
\hline & 3. $>3$ & $20(4.9 \%)$ \\
\hline \multirow[t]{2}{*}{ WFH policy } & 1. No & $78(19.2 \%)$ \\
\hline & 2. Yes & $328(80.8 \%)$ \\
\hline \multirow[t]{4}{*}{ BMI } & 1. Underweight & $21(5.2 . \%)$ \\
\hline & 2. Normal & $116(28.6 \%)$ \\
\hline & 3. Overweight & $84(20.7 \%)$ \\
\hline & 4. Obese & $185(45.6 \%)$ \\
\hline \multirow[t]{4}{*}{ Job strain } & 1. High Strain & $37(9.1 \%)$ \\
\hline & 2. Low Strain & $155(38.2 \%)$ \\
\hline & 3. Passive Jobs & $126(31.0 \%)$ \\
\hline & 4. Active Jobs & $88(21.7 \%)$ \\
\hline Work-life balance & & $3.80(0.66)$ \\
\hline Job security & & $3.20(1.20)$ \\
\hline Well-being & & $61.8(22.56)$ \\
\hline \multirow[t]{2}{*}{ Upper limb } & 1. No & $106(26.1 \%)$ \\
\hline & 2. Yes & $300(73.9 \%)$ \\
\hline \multirow[t]{2}{*}{ Lower limb } & 1. No & $245(60.3 \%)$ \\
\hline & 2. Yes & $161(39.7 \%)$ \\
\hline \multirow[t]{2}{*}{ Low back pain } & 1. No & $304(74.9 \%)$ \\
\hline & 2. Yes & $102(25.15)$ \\
\hline
\end{tabular}




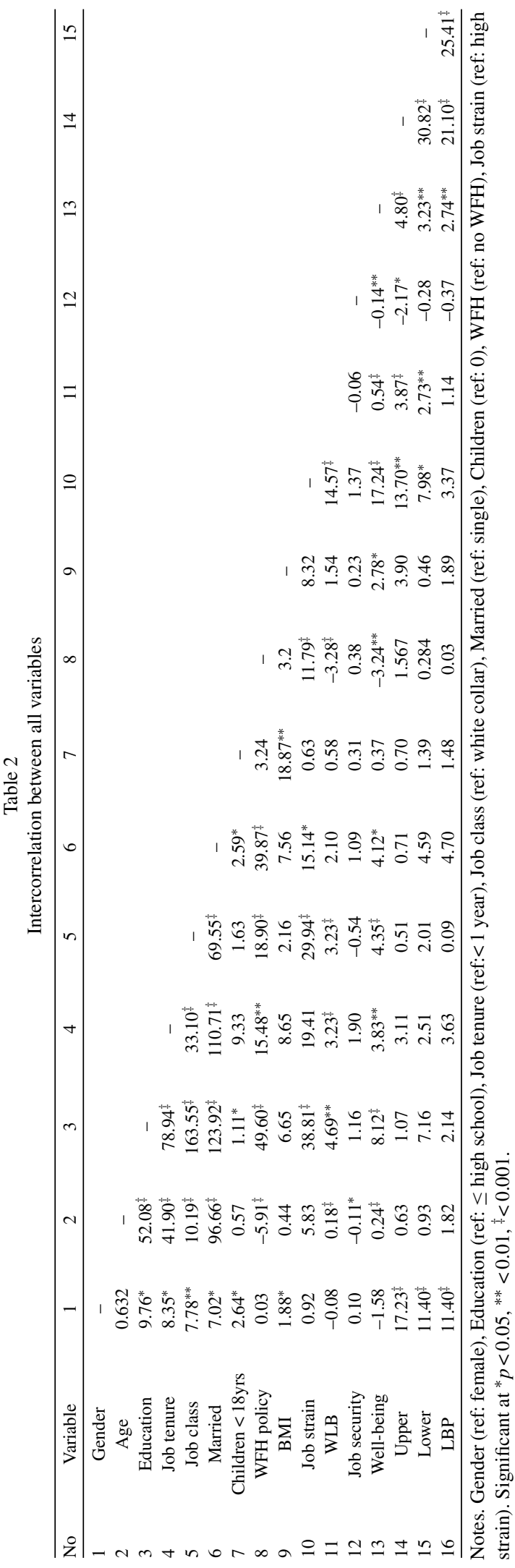

\subsection{Correlation analysis}

Table 2 shows the intercorrelations of the study variables. WLB and job security were significantly associated with well-being (all $p<0.01$ ). Since only demographic characteristic gender was significantly correlated with each body region (all $p<0.001$ ), then we included it as a covariate in our further mediation analysis. Job strain was independently associated with each region of MS symptoms while WLB was associated with neck/shoulder/upper body parts $(p<0.001)$, lower body part $(p<0.01)$, but not with low-back discomforts $(p=0.25)$. Job insecurity factor was correlated with upper body region but neither with lower part $(p=0.78)$ nor back pain $(p=0.71)$. Employees' well-being was significantly correlated to the three areas of pain (all $p<0.001)$ in the opposite directions.

\subsection{Mediation model}

The significant differences in well-being levels across job strain groups were not observed (path $a$ in Table 3 upper-left corner). On the other hand, WLB $(b=18.12, p<0.001)$ and job security $(b=-2.04$, $p<0.01)$ were associated with well-being in the expected direction. The $b$ path of the relationship between well-being and musculoskeletal symptoms shows that for every one unit increases in the wellbeing score, there was significantly 0.98 lower odds of an individual experiencing pain in the upper body parts $(p<0.001)$. On the opposite, the odds of having lower limb symptoms $(p=0.07)$ and low back pains $(p=0.03)$ were not statistically significant. The direct effects analysis (path $c^{\prime}$, see Fig. 3) reveals that job strain, WLB, and job security did not influence directly the prevalence of MS symptoms in each body region. Our mediation model analysis shows that after controlling gender, the indirect effect coefficient of the relationship between job-strain and each MS symptom through well-being is not significant (all 99\% Bootstrap CIs included zero, see Table 3). Similarly, the role of well-being on the relationship between job security and MS symptoms at the upper body part $(99 \% \mathrm{CI}=-0.003,0.116)$, lower limb $(99 \% \mathrm{CI}=-0.008,0.07)$, and low back pain $(99 \% \mathrm{CI}=-0.006,0.082)$ did not exist. On the other hand, well-being fully mediated the relationship between WLB and the prevalence of musculoskeletal symptoms in the upper body part $(\mathrm{OR}=0.71,99 \%$ $\mathrm{CI}=-0.772,-0.004)$ and low back $(\mathrm{OR}=0.78,99 \%$ $\mathrm{CI}=-0.065,-0.07)$, but not in the lower limb $(99 \%$ 
$\mathrm{CI}=-0.471,0.081)$. These values reveal that for one unit decreased work-life balance, an individual's likelihood of suffering MS pain increased $71 \%$ in the upper body part and $78 \%$ in the low back.

\section{Discussion}

This study aims to evaluate the mediation effect of psychological well-being on the relationship between specific psychosocial factors and the prevalence of musculoskeletal pain during the pandemic. Our findings show that psychological well-being completely mediated the association of work-life balance with upper and low back MS symptoms, suggesting that lower levels of well-being states arising from reduced work-life balance may lead to more upper and low back complaints. These findings were in support of Bonger and colleagues [13], who had proposed several pathways in which psychosocial factors can induce musculoskeletal pain through stress responses either directly or indirectly. This finding were aligned with the ecological model by Sauter and Swanson [17] and the balance theory by Carayon et al. [11] who argued that stress responses play a key role in the relationship between physical ergonomics and psychosocial risk factors and MSDs.

However, we did not find the direct effect of worklife balance irrespective of stress reactions, implying that there is no additional explanation regarding the mechanisms linking work-life balance to upper part and low back symptoms. This effect occurs entirely through a mechanism of well-being as hypothesized. This result is also consistent with previous studies concurrently examining (different types of) psychosocial stressors, mental health or psychological strain, and a variety of MS pain [21, 24, 60]. Reduced well-being may increase muscle tone or affect other physiological mechanisms, which may lead to the occurrence and development of musculoskeletal symptoms [48, 49]. Accordingly, the present study highlights the role of psychological well-being - as a mediating variable - in understanding how work-life balance, an ability to manage work and life responsibilities, may contribute to an individual's physical health, in particular MSDs during the pandemic.

In addition to indirect effect findings, both worklife balance and job security had significant path coefficients to psychological well-being, suggesting employees with lower work-life balance and greater job insecurity can have a significant impact on more distress which are in line with previous works both beyond $[32,44]$ and during the pandemic $[30,41$, 61]. These results support Minotte et al. [39], who emphasized the conflict roles between work-family life and pervasive job insecurity are two of the most pressing challenges facing contemporary workers.

Contrary to our expectation, job strain and job security were not important risk factors to wellbeing and the prevalence of MS symptoms which are inconsistent with prior studies either under normal circumstances $[25,38,47]$ or in the pandemic context $[28,29,62,63]$. These results indicate that psychosocial aspect outside the direct work environment (work life-balance) is more challenging for employees during the pandemic, as highlighted by earlier studies [30,64], when being compared to psychosocial factors related to work. Work's interference into family life became more important as the house became the primary location for educating children, and disregarding or neglecting these demands meant potentially harming their development. In normal situation, some scholars $[35,44]$ have also suggested exploring the work-life balance issues on MSDs rather than focus mainly on well-being and mental health, and other negative health behaviors.

We recognize some possible reasons for the lack association between job strain, well-being, and the MS symptoms. First, it might be due to the majority characteristics of our respondents were white-collar workers $(73.4 \%)$ from the general working population while previous research in the pandemic context were mainly focused on health professionals [28, 29]. Besides, high strain jobs are most commonly reported among blue-collar employees working in higher susceptible to MS injuries such as manufacturing and logistic industries $[65,66]$. Second, many organizations made several adjustment to help their employees adapt to and deal with major changes in the work and social environment [31, 67]. For example, the managers eased their expectation for work capacity, productivity, intensity, or other corresponding job-related demands. Furthermore, the sudden implementation of working from home arrangement - as reported by $80 \%$ of our sample - also offers more autonomy and flexibility [67]. Thus, lowered work expectations seem to be above and beyond their perceived job strain which might also explain why compared to other job strain groups, respondents in the high strain group did not exert their perceived well-being effects to the occurrence of musculoskeletal symptoms. 
Table 3

Mediation effect

\begin{tabular}{|c|c|c|c|c|c|c|c|c|c|c|c|c|c|c|c|}
\hline \multirow[t]{3}{*}{ Variables } & \multirow{2}{*}{\multicolumn{3}{|c|}{$\begin{array}{c}\text { Path } a \\
\text { Well-being }\end{array}$}} & \multicolumn{12}{|c|}{ Path $c^{\prime}$ (direct effect) } \\
\hline & & & & \multicolumn{4}{|c|}{ Upper part } & \multicolumn{4}{|c|}{ Lower limb } & \multicolumn{4}{|c|}{ Low back } \\
\hline & $b$ & SE & $p$-value & $b$ & SE & OR & $p$-value & $b$ & SE & OR & $p$-value & $b$ & SE & OR & $p$-value \\
\hline Gender (female) & 3.39 & 1.87 & 0.070 & -0.97 & 0.24 & 0.38 & $<0.001^{*}$ & -0.43 & 0.21 & 0.65 & 0.039 & -0.76 & 0.24 & 0.47 & 0.002 \\
\hline HS vs LS & 12.12 & 2.69 & 0.204 & -0.16 & 0.39 & 0.86 & 0.693 & -0.45 & 0.31 & 0.63 & 0.140 & -0.01 & 0.35 & 0.99 & 0.971 \\
\hline HS vs passive & 7.54 & 2.91 & 0.907 & -0.14 & 0.43 & 0.87 & 0.741 & -0.04 & 0.32 & 0.96 & 0.894 & 0.30 & 0.36 & 1.34 & 0.411 \\
\hline HS vs active & 8.13 & 2.92 & 0.628 & -0.96 & 0.40 & 0.38 & 0.018 & -0.40 & 0.33 & 0.67 & 0.230 & -0.25 & 0.38 & 0.78 & 0.522 \\
\hline Work-life balance & 18.12 & 1.42 & $<0.001^{* *}$ & -0.40 & 0.23 & 0.67 & 0.075 & -0.24 & 0.19 & 0.79 & 0.198 & 0.05 & 0.21 & 1.05 & 0.823 \\
\hline \multirow[t]{2}{*}{ Job security } & -2.04 & 0.79 & $0.009^{*}$ & 0.16 & 0.10 & 1.17 & 0.122 & -0.01 & 0.09 & 0.99 & 0.872 & 0.00 & 0.10 & 1.00 & 0.971 \\
\hline & & & & \multicolumn{12}{|c|}{ Path $b$} \\
\hline \multirow[t]{4}{*}{ Well-being } & - & - & - & -0.02 & 0.01 & 0.98 & $0.007^{*}$ & -0.01 & 0.01 & 0.99 & 0.068 & -0.01 & 0.01 & 0.99 & 0.033 \\
\hline & \multicolumn{15}{|c|}{ Indirect effect } \\
\hline & \multicolumn{5}{|c|}{ Upper } & \multicolumn{5}{|c|}{ Lower } & \multicolumn{5}{|c|}{ Low Back } \\
\hline & $b$ & SE & OR & \multicolumn{2}{|c|}{$99 \%$ CI } & $b$ & SE & OR & \multicolumn{2}{|c|}{$99 \%$ CI } & $b$ & SE & OR & \multicolumn{2}{|c|}{$99 \%$ CI } \\
\hline HS vs LS & -0.23 & 0.11 & 0.80 & -0.511 & 0.057 & -0.10 & 0.08 & 0.90 & -0.373 & 0.073 & -0.16 & 0.09 & 0.85 & -0.435 & 0.046 \\
\hline HS vs passive & -0.15 & 0.09 & 0.86 & -0.462 & 0.008 & -0.06 & 0.06 & 0.94 & -0.264 & 0.052 & -0.10 & 0.07 & 0.91 & -0.319 & 0.031 \\
\hline HS vs active & -0.16 & 0.10 & 0.85 & -0.494 & 0.010 & -0.07 & 0.06 & 0.93 & -0.286 & 0.056 & -0.11 & 0.07 & 0.90 & -0.365 & 0.036 \\
\hline Work-life balance & -0.35 & 0.14 & $0.71^{\ddagger}$ & -0.772 & -0.004 & -0.18 & 0.10 & 0.83 & -0.471 & 0.081 & -0.36 & 0.11 & $0.70^{\ddagger}$ & -0.655 & -0.071 \\
\hline Job security & 0.04 & 0.02 & 1.04 & -0.003 & 0.116 & 0.02 & 0.01 & 1.02 & -0.008 & 0.070 & 0.03 & 0.02 & 1.03 & -0.006 & 0.082 \\
\hline
\end{tabular}

Notes. Path $a$ (psychosocial $\sim$ well-being), path $b$ (well-being $\sim$ MS symptoms), path $c^{\prime}$ (direct effect: psychosocial $\sim$ MS symptoms), Indirect effect (Psychosocial $\sim$ Well-being $\sim$ MS symptoms).

HS $=$ High strain, LS $=$ Low strain. ${ }^{*}$ significant at $p<0.01$ after Bonferroni correction, ${ }^{* *}<0.001$, Indirect effect: $\ddagger$ Significant at $99 \%$ Bootstrap Confidence Interval (CI) did not include zero. 
With respect to job security, although there is a significant path between job security and well-being but no evidence of well-being would mediate the effect of job security on the occurrence of MS symptoms. It might be explained that the use of single-item measure could not capture different facets of security which might not be only uncertainty about the fear of losing one's job, but also financial crisis and risk of not being able to adapt with changes to tasks and working conditions $[14,36,68]$. Nevertheless, the use of single-item measure of job security was also adopted prior studies [62, 63] because of its more convenient and feasible features in the current time of crisis.

In spite of these insignificant paths, we may not rule out the association between job strain and job security and MSDs. Our univariate analysis (see Table 2) shows that job strain and job insecurity were associated with upper body part symptoms which indicate that their impact on MS symptoms may be exerted through some other unobserved mediators. Some scholars demonstrated other psychological strain such as depression symptoms, anxiety, or emotional resilience may mediate the association between these risk factors and MSDs [21, 24, 68]. Besides, in this study we used more conservative confidence interval $(99 \%)$ instead of $95 \%$ because of multiple tests. Different results' interpretations might be expected depending on disciplinary norms, or other researchers' beliefs about the relative risks and costs of Type I relative to Type II errors [59].

Meanwhile, we were also unable to find evidence of an association between each psychosocial factor, well-being, and risk of experiencing lower limb pain, or that well-being would mediate the effect of these factors on lower limb pain. A plausible explanation might be attributed to our sample mostly consisted of white-collar workers whose jobs are characterized by computer-based work. Such work is strongly related to the prolonged sedentary position which may lead to the prevalence of upper body and low back pains, rather than lower limb pains, and can be exacerbated during working from home [3]. Furthermore, most of the clinical and psychological research on the interrelationships between psychosocial factors and MSDs, as synthesized in recent systematic reviews, focused on the MSDs in the neck, shoulder, and lower back $[14,19]$. Very few studies have been undertaken to assess the risk factors for lower limb pains which have been also the lowest rate suffered among the working population as compared to other body regions [24, $45,69]$.

\subsection{Practical implication}

Our findings suggest the importance of maintaining well-being to reduce the occurrence of adverse health outcomes in terms of the prevalence of musculoskeletal symptoms. While in the past, preserving musculoskeletal health and the prevention of MSDs were mainly focused on physical activity or traditional ergonomics and human engineering, recent studies showed the important roles of psychosocial stressors through the mediation of psychological health. The pandemic situation has been strongly associated with impaired psychological well-being which may lead to adverse physical health outcomes such as MSDs, so the organization can help maintain employees' well-being by keeping stressors to a minimum [36]. Our finding confirmed that during the pandemic the psychosocial risk factor is likely to move toward work-life balance. Therefore an organization may develop strategies to support workers to meet both their work and life responsibilities, for example by increasing flexibility in workingtime arrangement, focusing on the quality rather than quantity of work, and providing employees who are experiencing work-life conflict with psychological well-being support [36].

\subsection{Limitations and future research}

One of our study limitations was the cross-sectional study design which limits causal inference. We are also aware of the limitations that, due to the current crisis time and resource constraints, the chosen method and sampling strategies through online questionnaires raise validity concerns. Our sampling approach was a combination of convenience and snowball sampling strategy in which participants could invite others in their network. This approach introduced bias because the technique itself increases the risk that the sample will not be representative of the population. Generalizability is limited because our sample was predominantly highly educated individuals and white-collar workers. However, this sampling strategy allowed us to gain preliminary information on an important and rapidly evolving issue. Next, our sole reliance on self-report data may also raise reporting and selection bias. Therefore, the findings should be taken with caution. Future studies should use more rigid research methods by adopting a longitudinal study design and a probability sampling technique to better explain the causal links between psychosocial factors, mental well-being, and MS 
symptoms. Third, we did not evaluate ergonomic condition such as physical demands, workstation design, and work environment of which the combination with psychosocial risks can explain the model better [11]. Expansion of the further model could also integrate other psychosocial stressors such as leadership and social support which are of particular relevance to be explored during the current pandemic situation. Furthermore, selecting specific occupations or job position of interest, such as managers or teachers, is important for model validation. Finally, we did not assess the feedback loops of the influence of MS symptoms on psychosocial risk factors as suggested some MSDs models [11, 17]. Future research is required to evaluate these pathways employing a more advanced analysis.

Notwithstanding the above-mentioned drawbacks, this study provided preliminary evidence on the effect of COVID-19 on Indonesian employees' physical and psychological health. To our best knowledge, this is the first study to investigate the relationship between specific psychosocial factors during the pandemic and musculoskeletal pain through the wellbeing pathway which offers insights into the more complex relationship of the stress process model.

\section{Conclusion}

Some psychosocial risk factors may occur as a result of the COVID-19 crisis, inducing the risks for the development of MSDs and reduced psychological well-being. The current study's outcomes demonstrate that lower work-life balance is associated with reduced well-being which in turn lead to higher occurrences of musculoskeletal symptoms of the upper part and lower back during the pandemic. No evidence of the relationship between job strain, job security, well-being, and MS symptoms suggest that specific psychosocial risks may be more relevant for specific occupations and circumstances. To maintain employees' performance, organizations need to develop proper strategies to minimize role conflicts between work and personal life which could result in reduced well-being and in turn, musculoskeletal complaints.

\section{Acknowledgment}

The authors would like to thank Yoga Cahyadi Jati, MM (Energi Mega Persada), Setia Hermawati, $\mathrm{PhD}$ (University of Nottingham) who contributed to the initial research design and during data collection, and two anonymous reviewers for their critical and constructive feedback.

\section{Conflict of interest}

None of the authors have any conflict of interest to report.

\section{Funding}

The study was not supported by any funding organization.

\section{References}

[1] Zhang J, Lu H, Zeng H, Zhang S, Du Q, Jiang T, et al. The differential psychological distress of populations affected by the COVID-19 pandemic. Brain Behav Immun. 2020;87:4950. https://doi.org/10.1016/j.bbi.2020.04.031

[2] Shaukat N, Ali DM, Razzak J. Physical and mental health impacts of COVID-19 on healthcare workers: a scoping review. Int J Emerg Med 2020;13:40. https:// doi.org/10.1186/s12245-020-00299-5

[3] Moretti A, Menna F, Aulicino M, Paoletta M, Liguori S, Iolascon G. Characterization of home working population during covid-19 emergency: A cross-sectional analysis. Int J Environ Res Public Health 2020;17:1-13. https://doi.org/10.3390/ijerph17176284

[4] Hamouche S. COVID-19 and employees' mental health: stressors, moderators and agenda for organizational actions. Emerald Open Res 2020;2. https://doi.org/10.35241/ emeraldopenres.13550.1

[5] Arca M, Dönmezdil S, Durmaz ED. The effect of the COVID-19 Pandemic on anxiety, depression, and musculoskeletal system complaints in healthcare workers. Work 2021;69:47-54. https://doi.org/10.3233/wor-205014

[6] WHO. Musculoskeletal conditions 2021. https://www. who.int/news-room/fact-sheets/detail/musculoskeletalconditions (accessed May 8, 2021).

[7] Ministry of Health of the Republic of Indonesia. Hasil Riset Kesehatan Dasar Tahun 2018. vol. 53. 2019.

[8] Bergh LIV, Leka S, Zwetsloot GIJM. Tailoring Psychosocial Risk Assessment in the Oil and Gas Industry by Exploring Specific and Common Psychosocial Risks. Saf Health Work 2018;9:63-70. https://doi.org/10.1016/j.shaw.2017.05.001

[9] Buckle P. Ergonomics and musculoskeletal disorders: Overview. Occup Med (Chic Ill) 2005;55:164-7. https://doi.org/10.1093/occmed/kqi081

[10] WHO. Mental health in the workplace 2019. https://www. who.int/mental_health/in_the_workplace/en/ (accessed Oct ober 20, 2020).

[11] Carayon P, Smith MJ, Haims MC. Work organization, job stress, and work-related musculoskeletal disorders. Hum Factors 1999;41:644-63. https://doi.org/10.1518/001 872099779656743 
[12] ILO. Psychosocial Factors at Work: Recognition and Control. 1986. https://doi.org/10.1007/978-1-4471-0879-5_5

[13] Bongers PM, De Winter CR, Kompier MAJ, Hildebrandt VH. Psychosocial factors at work and musculoskeletal disease. Scand J Work Environ Heal 1993;19:297-312. https://doi.org/10.5271/sjweh.1470

[14] Roquelaure Y. Musculoskeletal Disorders and Psychosocial Factors at Work. Brussels: 2018. https://doi. org/10.2139/ssrn.3316143

[15] Hurrell JJ, Nelson DL, Simmons BL. Measuring job stressors and strains: where we have been, where we are, and where we need to go. J Occup Health Psychol 1998;3:36889. https://doi.org/10.1037/1076-8998.3.4.368.

[16] Huang GD, Feuerstein M, Sauter SL. Occupational stress and work-related upper extremity disorders: Concepts and models. Am J Ind Med 2002;41:298-314. https://doi.org/10.1002/ajim.10045.

[17] Sauter S, Swanson N. An ecological model of musculoskeletal disorders in office work. In: Moon S, Sauter S, editors. Psychosoc. Factors Musculoskelet. Disord. Off. Work, London, United Kingdom: Taylor \& Francis; 1996, p. 3-22.

[18] Haukka E, Leino-Arjas P, Ojajärvi A, Takala EP, Viikari-Juntura E, Riihimäki H. Mental stress and psychosocial factors at work in relation to multiple-site musculoskeletal pain: A longitudinal study of kitchen workers. Eur J Pain 2011;15:432-8. https://doi.org/10.1016/ j.ejpain.2010.09.005.

[19] Hauke A, Flintrop J, Brun E, Rugulies R. The impact of work-related psychosocial stressors on the onset of musculoskeletal disorders in specific body regions: A review and metaanalysis of 54 longitudinal studies. Work Stress 2011;25:243-56. https://doi.org/10.1080/02678373. 2011.614069.

[20] Kodom-Wiredu JK. The Relationship between Firefighters' Work Demand and Work-related Musculoskeletal Disorders: The Moderating Role of Task Characteristics. Saf Health Work 2019;10:61-6. https://doi.org/10. 1016/j.shaw.2018.05.004.

[21] Eatough EM, Way JD, Chang CH. Understanding the link between psychosocial work stressors and work-related musculoskeletal complaints. Appl Ergon 2012;43:554-63. https://doi.org/10.1016/j.apergo.2011.08.009.

[22] Di Stefano G, Venza G, Aiello D. Associations of Job Insecurity With Perceived Work-Related Symptoms, Job Satisfaction, and Turnover Intentions: The Mediating Role of Leader-Member Exchange and the Moderating Role of Organizational Support. Front Psychol 2020;11:1329. https://doi.org/10.3389/fpsyg.2020.01329.

[23] Åhlin JK, Halonen JI, Madsen IEH, Rugulies R, Sørensen JK, Magnusson Hanson LL. Interrelationships between job demands, low back pain and depression: A four-way decomposition analysis of direct and indirect effects of job demands through mediation and/or interaction. J Affect Disord 2021;282:219-26. https://doi.org/10. 1016/j.jad.2020.12.061

[24] Sprigg CA, Stride CB, Wall TD, Holman DJ, Smith PR. Work Characteristics, Musculoskeletal Disorders, and the Mediating Role of Psychological Strain: A Study of Call Center Employees. J Appl Psychol 2007;92:1456-66. https://doi.org/10.1037/0021-9010.92.5.1456

[25] Amiri S, Behnezhad S. Is job strain a risk factor for musculoskeletal pain? A systematic review and meta-analysis of 21 longitudinal studies. Public Health 2020;181:158-67. https://doi.org/10.1016/j.puhe.2019.11.023
[26] Bernal D, Campos-Serna J, Tobias A, Vargas-Prada S, Benavides FG, Serra C. Work-related psychosocial risk factors and musculoskeletal disorders in hospital nurses and nursing aides: A systematic review and metaanalysis. Int J Nurs Stud 2015;52:635-48. https://doi.org/ 10.1016/j.ijnurstu.2014.11.003.

[27] Karasek R, Theorell T. Healthy Work: Stress, Productivity, and the Reconstruction of Working Life. New York, USA: Basic Books; 1990. https://doi.org/10.1086/417423

[28] TAŞ BG, Özceylan G, Öztürk GZ, Toprak D. Evaluation of Job Strain of Family Physicians in COVID-19 Pandemic Period- An Example from Turkey. J Community Health 2020. https://doi.org/10.1007/s10900-020-00950-5.

[29] Poncelet G, Le Bourgeois F, Nicolas-Robin A. Job stress in paediatric ICU staff caring for adult COVID-19 patients: An observational study during the first COVID19 wave. Anaesth Crit Care Pain Med 2021;40:100810. https://doi.org/10.1016/j.accpm.2021.100810.

[30] Schieman S, Badawy PJ, A. Milkie M, Bierman A. WorkLife Conflict During the COVID-19 Pandemic. Socius Sociol Res a Dyn World 2021;7:1-19. https://doi.org/ $10.1177 / 2378023120982856$.

[31] Carnevale JB, Hatak I. Employee adjustment and well-being in the era of COVID-19: Implications for human resource management. J Bus Res 2020;116:183-7. https://doi.org/ 10.1016/j.jbusres.2020.05.037.

[32] Sirgy MJ, Lee DJ. Work-Life Balance: an Integrative Review. Appl Res Qual Life 2018;13:229-54. https://doi.org/10.1007/s11482-017-9509-8.

[33] Haar JM, Russo M, Suñe A, Ollier-Malaterre A. Outcomes of work-life balance on job satisfaction, life satisfaction and mental health: A study across seven cultures. J Vocat Behav 2014;85:361-73. https://doi.org/10.1016/j.jvb.2014.08.010.

[34] Chung G, Chan XW, Lanier P, Ju PWY. Associations Between Work-Family Balance, Parenting Stress, and Marital Conflicts During COVID-19 Pandemic in Singapore 2020:1-35. https://doi.org/10.31219/osf.io/nz9s8.

[35] Hämmig O, Knecht M, Läubli T, Bauer GF. Work-life conflict and musculoskeletal disorders: a cross-sectional study of an unexplored association. BMC Musculoskelet Disord 2011;12:60. https://doi.org/10.1186/1471-2474-12-60.

[36] ILO. Managing work-related psychosocial risks during the COVID-19 pandemic. 2020.

[37] Kim MG, Kim K-S, Ryoo J-H, Yoo S-W. Relationship between Occupational Stress and Work-related Musculoskeletal Disorders in Korean Male Firefighters. Ann Occup Environ Med 2013;25:1. https://doi.org/ 10.1186/2052-4374-25-9.

[38] Amin NA, Nordin R, Fatt QK, Noah RM, Oxley J. Relationship between psychosocial risk factors and workrelated musculoskeletal disorders among public hospital nurses in Malaysia. Ann Occup Environ Med 2014;26:1-9. https://doi.org/10.1186/s40557-014-0023-2.

[39] Minnotte KL, Yucel D. Work-Family Conflict, Job Insecurity, and Health Outcomes Among US Workers. Soc Indic Res 2018;139:517-40. https://doi.org/10.1007/s11205-0171716-z.

[40] Wilson JM, Lee J, Fitzgerald HN, Oosterhoff B, Sevi B, Shook NJ. Job Insecurity and Financial Concern During the COVID-19 Pandemic Are Associated With Worse Mental Health. J Occup Environ Med 2020;62:686-91. https://doi.org/10.1097/JOM.0000000000001962

[41] Russo C, Terraneo M. Mental Well-being Among Workers: A Cross-national Analysis of Job Insecurity Impact 
on the Workforce. Soc Indic Res 2020;152:421-42. https://doi.org/10.1007/s11205-020-02441-5

[42] Kuper H, Marmot M. Job strain, job demands, decision latitude, and risk of coronary heart disease within the Whitehall II study. J Epidemiol Community Health 2003;57:147-53. https://doi.org/10.1136/jech.57.2.147

[43] Theorell T, Hammarström A, Gustafsson PE, Hanson LM, Janlert U, Westerlund H. Job strain and depressive symptoms in men and women: A prospective study of the working population in Sweden. J Epidemiol Community Health 2014;68:78-82. https://doi.org/10.1136/jech-2012202294

[44] Nützi M, Koch P, Baur H, Elfering A. Work-family conflict, task interruptions, and influence at work predict musculoskeletal pain in operating room nurses. Saf Health Work 2015;6:329-37. https://doi.org/10.1016/j.shaw.2015.07.011

[45] Harcombe H, McBride D, Derrett S, Gray A. Physical and psychosocial risk factors for musculoskeletal disorders in New Zealand nurses, postal workers and office workers. Inj Prev 2010;16:96-100. https://doi.org/10. 1136/ip.2009.021766

[46] Lee JH, Lee J, Lee KS. Moderated Mediation Effect of Mindfulness on the Relationship Between Muscular Skeletal Disease, Job Stress, and Turnover Among Korean Firefighters. Saf Health Work 2020;11:222-7. https://doi.org/10.1016/j.shaw.2020.03.006

[47] Hämmig O. Work- and stress-related musculoskeletal and sleep disorders among health professionals: a crosssectional study in a hospital setting in Switzerland. BMC Musculoskelet Disord 2020;21:319. https://doi.org/ 10.1186/s12891-020-03327-w

[48] Landsbergis PA, Schnall PL, Warren K, Pickering TG, Schwartz JE. Association between ambulatory blood pressure and alternative formulations of job strain. Scand J Work Environ Heal 1994;20:349-63. https://doi.org/ 10.5271/sjweh. 1386

[49] Schleifer LM, Ley R. End-tidal PCO 2 as an index of psychophysiological activity during VDT data-entry work and relaxation*. Ergonomics 1994;37:245-54. https://doi. org/10.1080/00140139408963642

[50] Huppert FA. Psychological Well-being: Evidence Regarding its Causes and Consequences. Appl Psychol Heal Well-Being 2009;1:137-64. https://doi.org/10.1111/j.17580854.2009.01008.x

[51] Karasek R, Brisson C, Kawakami N, Houtman I, Bongers $\mathrm{P}$, Amick B. The Job Content Questionnaire (JCQ): an instrument for internationally comparative assessments of psychosocial job characteristics. J Occup Health Psychol 1998;3:322-55. https://doi.org/10.1037/1076-8998.3.4.322

[52] Rasmussen-Barr E, Grooten WJA, Hallqvist J, Holm LW, Skillgate E. Are job strain and sleep disturbances prognostic factors for low-back pain? a cohort study of a general population of working age in Sweden. J Rehabil Med 2017;49:591-7. https://doi.org/10.2340/16501977-2249

[53] Fransson EI, Nyberg ST, Heikkilä K, Alfredsson L, Bacquer DD, Batty GD, et al. Comparison of alternative versions of the job demand-control scales in 17 European cohort studies: The IPD-Work consortium. BMC Public Health 2012;12:62. https://doi.org/10.1186/1471-2458-12-62

[54] Briggs SR, Cheek JM. The role of factor analysis in the development and evaluation of personality scales. J Pers 1986;54:106-48. https://doi.org/10.1111/j.14676494.1986.tb00391.x

[55] Theorell T, Karasek RA. Current issues relating to psychosocial job strain and cardiovascular disease research. J Occup Health Psychol 1996;1:9-26. https://doi. org/10.1037/1076-8998.1.1.9

[56] Topp CW, Østergaard SD, Søndergaard S, Bech P. The WHO-5 Well-Being index: A systematic review of the literature. Psychother Psychosom 2015;84:167-76. https://doi.org/10.1159/000376585

[57] Schütte S, Chastang JF, Malard L, Parent-Thirion A, Vermeylen G, Niedhammer I. Psychosocial working conditions and psychological well-being among employees in 34 European countries. Int Arch Occup Environ Health 2014;87:897-907. https://doi.org/10.1007/s00420014-0930-0

[58] Hayes AF. Introduction to Mediation, Moderation, and Conditional Process: A Regression-Based Approach. 2nd Ed. New York, USA: The Guilford Press; 2018.

[59] Hayes AF, Preacher KJ. Statistical mediation analysis with a multicategorical independent variable. Br J Math Stat Psychol 2013:1-20. https://doi.org/10.1111/bmsp.12028

[60] Ng YM, Voo P, Maakip I. Psychosocial factors, depression, and musculoskeletal disorders among teachers. BMC Public Health 2019;19:1-10. https://doi.org/10.1186/s12889-0196553-3

[61] Di Stefano G, Venza G, Aiello D. Associations of Job Insecurity With Perceived Work-Related Symptoms, Job Satisfaction, and Turnover Intentions: The Mediating Role of Leader-Member Exchange and the Moderating Role of Organizational Support. Front Psychol 2020;11. https://doi.org/10.3389/fpsyg.2020.01329

[62] Wilson JM, Lee J, Fitzgerald HN, Oosterhoff B, Sevi B, Shook NJ. Job Insecurity and Financial Concern during the COVID-19 Pandemic are Associated with Worse Mental Health. J Occup Environ Med 2020;62:686-91. https://doi.org/10.1097/JOM.0000000000001962

[63] Song L, Wang Y, Li Z, Yang Y, Li H. Mental Health and Work Attitudes among People Resuming Work during the COVID-19 Pandemic: A Cross-Sectional Study in China. Int J Environ Res Public Health 2020;17. https://doi.org/10.3390/ijerph17145059

[64] Gragnano A, Simbula S, Miglioretti M. Work-Life Balance: Weighing the Importance of Work-Family and Work-Health Balance. Int J Environ Res Public Health 2020;17:907. https://doi.org/10.3390/ijerph17030907

[65] Varela-Mato V, Clemes SA, King J, Munir F. Associations between Musculoskeletal Conditions Risk, Sedentary Behavior, Sleep, and Markers of Mental Health: A Cross-Sectional Observational Study in Heavy Goods Vehicle Drivers. Musculoskeletal Conditions Risk in HGV Drivers. J Occup Environ Med 2019;61:437-43. https://doi. org/10.1097/JOM.0000000000001587

[66] Gerr F, Fethke NB, Anton D, Merlino L, Rosecrance $\mathrm{J}$, Marcus $\mathrm{M}$, et al. A prospective study of musculoskeletal outcomes among manufacturing workers: II. effects of psychosocial stress and work organization factors. Hum Factors 2014;56:178-90. https://doi.org/10.1177/ 0018720813487201

[67] Sutarto AP, Wardaningsih S, Putri WH. Work from Home: Indonesian Employees' Mental Well-Being and Productivity during the COVID-19 Pandemic. Int J Work Heal Manag 2021.

[68] Aguiar-Quintana T, Nguyen H, Araujo-Cabrera Y, SanabriaDíaz JM. Do job insecurity, anxiety and depression caused by the COVID-19 pandemic influence hotel employees' self-rated task performance? The moderating role of employee resilience. Int J Hosp Manag 2021;94. https://doi.org/10.1016/j.ijhm.2021.102868 
[69] Herr RM, Bosch JA, Loerbroks A, van Vianen AEM, Jarczok MN, Fischer JE, et al. Three job stress models and their relationship with musculoskeletal pain in blue- and white-collar workers. J Psychosom Res 2015;79:340-7. https://doi.org/10.1016/j.jpsychores.2015.08.001 